\title{
Ovarian Differentiation in the Medaka, Oryzias latipes, with Special Reference to the Gradient of the Differentiation
}

\author{
Hiromasa YoshIKAWA* and Mikio OGURI* \\ (Received October 1, 1980)
}

\begin{abstract}
The gradient of the ovarian differentiation in the medaka, Oryzias latipes, was examined numerically in the present investigation. Germ cell in meiosis was employed as a criterion for the differentiation of ovary. In the fry of $4.9+0.10 \mathrm{~mm}$ in length (mean \pm S.D., $\mathrm{n}=30$ ) at 2 days $(26 \pm$ $2 \mathrm{~b}$ ) after hatching, the germ cells in meiotic prophase were detected for the first time, but the somatic cells of the ovary showed no structural differentiation. According to YamaMoTo, there was an antero-posterior gradient in the gonadal sex differentiation of the medaka.

In the present investigation, however, such a gradient was not recognizable. The ovarian differentiation proceeded at randon without any gradient. From the present results, it was revealed that the ovarian differentiation began before the completion of the formation of the primordial gonad, and that there was a difference in the time of the differentiation between the right lobe and the left lobe of the ovary; the right lobe differentiated at an earlier stage than the left lobe.
\end{abstract}

In general, fish gonads are elongated organs situated below the swim-bladder in the peritoneal cavity. This situation is also applicable to the primordial gonad and the developing gonad. Consequently, it is conceivable that the anterior region of indifferent gonad is different from the posterior region of the same gonad with respect to the sensitivity and the responsiveness to chemical substances, the time of sex differentiation and so on. We found out a gradient by chance in the gonadal sex differentiation of a cichlid fish, Tilapia zillii ${ }^{1)}$. In the case of $T$. zillii, the sex differentia. tion began at the anterior region of gonad, irrespective of sex; spermatogenesis, oogenesis, the formation of ovarian cavity and the appearance of testisova tended to proceed in an antero-posterior sequence. Among them, the gradient was the most clear-cut in the formation of the ovarian cavity.

The same gradient as that in $T$. zillii was known in the medaka, Oryzias latipes. YAMAMOTO ${ }^{2,8)}$ and YAMAMOTO and MATSUDA ${ }^{4)}$ pointed out that there was an antero-posterior gradient in the gonadal sex differentiation of the medaka; the posterior region of gonad remained in indifferent state for a certain period even after the onset of sex differentiation at the anterior region. In the medaka, an intersex was rarely produced under the condition that the dosage level of sex hormone or the period of hormonal treatment was inadequate ${ }^{2, b-7)}$.
YAMAMOTO ${ }^{21}$ interpreted the cause for the occurrence of andro-intersex (XY) with the gradient as follows. The anterior region of gonad differentiated into testicular tissue owing to the sex inductor substance controlled by male sex-determining genes, while the posterior region in indifferent state was modified into ovarian tissue under the influence of administered estrogenic substance.

Any gradient in gonadal sex differentiation has not been reported in other fishes as far as we know. However, the same gradient as those in $T$. zillii and the medaka was reported in African clawed frog, Xenopus laevis. According to WrrsCHI ${ }^{\mathrm{B})}$, the gonadal sex differentiation of $X$. laevis progressed from the anterior region to the posterior end in the course of about a week. Similarly to the case of the medaka, the gradient of $X$. laevis was studied in relation to the occurrence of the intersex ${ }^{8-10}$. The gonad of genetic male treated with estrogen for 2 days within the week of sex differentiation developed into a mosaic gonad, consisted of ovarian and testicular components. Besides, the ovarian part corresponded to the differentiating part of gonad at the time of hormonal treatment, and shifted caudally with the age of the larvae.

If such a gradient really exists, it may be explained in two ways. (1) Gonadal differentiation and development merely proceed in an antero-posterior sequence. This idea may be supported to some extent with the fact that there was an antero-

* Fisheries Laboratory, Faculty of Agriculture, Nagoya University, Furo, Nagoya 464 (吉JI弘正 • 小聚幹郎：名古屋大学鼠学部水㢈学故室). 
posterior gradient in the formation of primordial gonad as well as in gonadal sex differentiation ${ }^{12,12)}$. According to $\mathrm{W}_{\mathrm{ITSCH}}{ }^{11)}$, primordial germ cells of anurans became separated from the entoderm in cephalo-caudal sequence, and those in the most cephalic position already reached the genital ridges when those located further caudally were still massed at the root of mesentery. (2) The most anterior part of gonad differentiates for the first time and induces the differentiation of the contiguous part in indifferent state located more caudally. Then, the newly differentiated parts induce the differentiation of the next parts one after another and eventually the most posterior part. If the second idea is right, the gradient should be a key to solve the problems about sex differentiation. However, there is no evidence about this. From this viewpoint, we already carried out the numerical analysis on the testicular differentiation of the medaka, in order to obtain an accurate informa. tion, using interstitial cell and germ cell in meiosis as the criteria for the differentiation of somatic and germinal elements, respectively ${ }^{13)}$. However, the testicular differentiation progressed at random without any gradient. In the present investigation we tried the numerical analysis on the ovarian differentiation of the medaka, in comparison with the testicular differentiation.

\section{Materials and Methods}

Broods of the genetically analysed d-rR strain of the medaka, Oryzias latipes, were used in the present investigation. This strain was first established in 1946 by Yamamoro ${ }^{14}$. In the strain, the sex genotypes are $\mathrm{X}^{\mathrm{r}} \mathrm{X}^{\mathrm{r}}$ for genetic female and $\mathrm{X}^{\mathrm{r}} \mathrm{Y}^{\mathrm{R}}$ for genetic male, where $\mathrm{r}$ and $\mathrm{R}$ stand for white and orange-red, respectively. The newly hatched fry were reared in the glass aquaria placed indoors at about $26^{\circ} \mathrm{C}$ under a $16 \mathrm{~h}-8 \mathrm{~h}$ lightdark cycle. They were fed on the powdered diet mixed with the commercial food for tropical fish and dried water-fleas. The rearing water was artificially aerated and changed every week.

At first, histological observation was carried out with 65 young females of 5.5 to $13.0 \mathrm{~mm}$ in length; for the sake of simplicity, the body length was expressed in $0.5 \mathrm{~mm}$ intervals. Secondly, in order to examine the process of the ovarian differentiation at earlier stages, 160 fish without sexing from the day to 5 days after hatching were studied. Fish were fixed in toto with Bouin's fluid, and properly trimmed following fixation. At auto- psy, they were measured for body length from the tip of the snout to the end of the caudal fin under anesthesia with MS222. Materials fixed in Bouin's fluid were dehydrated in alcohol and embedded in paraffin. Serial paraffin sections were cut transeversely at $5 \mu \mathrm{m}$ in thickness, and stained with Mayer's or Ehrlich's hematoxylin and eosin.

For the examination of the gradient in ovarian differentiation, germ cell in meiosis was employed as a criterion. Serial sections of the body portion including gonad were divided into ten parts; each part contained an equal number of the successive sections. The gradient is expressed in a bar chart. At the abscissa of the bar charts, the position of the divided parts in ovary is shown; "1" is the most anterior part of ovary and " 10 ". is the most posterior part. At the ordinate, the frequency of the appearance of germ cell in meiosis is shown; " 5 " means that germ cells in meiosis are found in half the sections and " 10 " in all the sections at each part.

\section{Results}

\section{Ovarian Differentiation at 5.5 to $13 \mathrm{~mm}$ Stage}

According to Yамамото:" the sex differentiation of the medaka began in the anterior region of gonad at $6.3 \mathrm{~mm}$ stage, and completed in the posterior region at about $11 \mathrm{~mm}$ stage. Then we examined histologically, in order to obtain an outline of a gradient in ovarian differentiation, 65 females of 5.5 to $13.0 \mathrm{~mm}$ in total length. The results of the numerical analysis for females of 6.0 to $11.0 \mathrm{~mm}$ in length are shown in the bar charts of Figs. 1-6. At a glance, we can plainly recognize that even at $6.0 \mathrm{~mm}$ stage sex differentiation is almost finished. Germ cells in meiosis employed as a criterion were recognizable at about all the parts, from " 1 " to " 10 " at the abscissa of the bar chart, in all females at $6.0 \mathrm{~mm}$ stage. At the stages more than $8.0 \mathrm{~mm}$ in length, they were of course detected in all the parts and moreover, their frequency of each part reached the plateau, " 10 " at the ordinate of the bar chart. The ovaries at $5.5 \mathrm{~mm}$ and $9.0 \mathrm{~mm}$ stages are shown in the microscopic pictures (Plate, 1 and 2). At these stages, we could not find out any gradient in the ovarian differentiation. As a second step, we examined the ovarian differentiation at earlier stages.

Ovarian Differentiation at the Day and the Next
Four Consecutive Days after Hatching
In the newly hatched fry of $4.6 \pm 0.11 \mathrm{~mm}$ in 


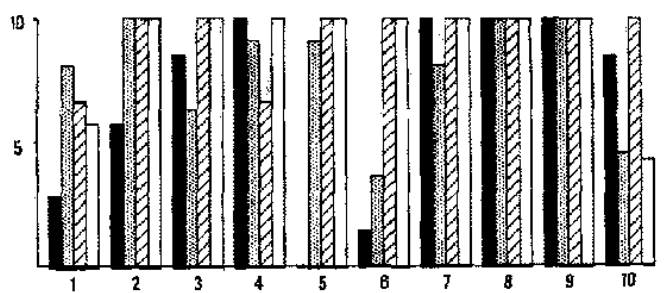

Fig. 1. A pattern for the differentiation of gem cells in the ovary at $6.0 \mathrm{~mm}$ stage. $n \ldots 4$. In this and the following Figs. (Figs. 1-6 and 9-12), 4 specimens are chosen as the representatives among specimens examined histologically and a total number of specimens at a stage is shown as $n=x$, for example, $\mathrm{n}=4$ at $6.0 \mathrm{~mm}$ stage. Besides, the data for specimens at $5.5,6.5,7.5,8.5,9.5,10.5$, $11.5,12.0,12.5$ and $13.0 \mathrm{~mm}$ stages are omitted on account of no marked difference. At the abscissa of the bar charts, the position of the divided parts in ovary is shown; " 1 " is the most anterior part and "10" is the most posterior part of ovary. At the ordinate, the frequency of the appearance of a criterion is shown; " 5 " means that germ cells in meiosis are found in half the sections and "10" in all the sections at each part. In the bar chart, four kinds of designs are used and the bars with a same design indicate a same specimen.

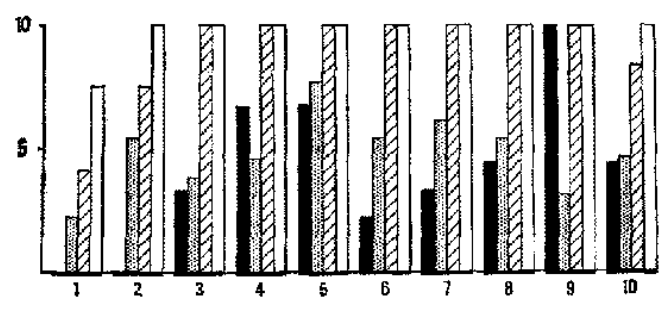

Fig. 2. A pattern for the differentiation of germ cells in the ovary at $7.0 \mathrm{~mm}$ stage. $\mathrm{n}=4$.

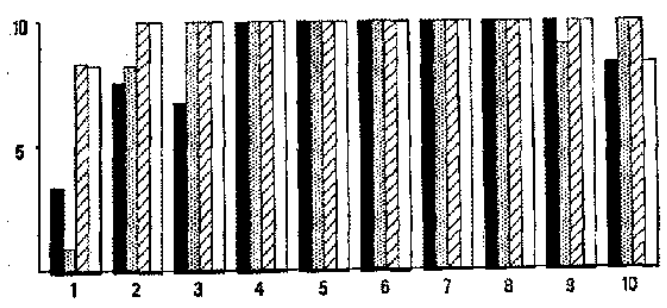

Fig. 3. A pattern for the differentiation of germ cells in the ovary at $8.0 \mathrm{~mm}$ stage. $\mathrm{n}=4$.

length (mean $\pm S . D, n=40$ ) within $4 \mathrm{~h}$ after hatching, two types of gonads were roughly distinguished. One type contained many germ cells (Plate,

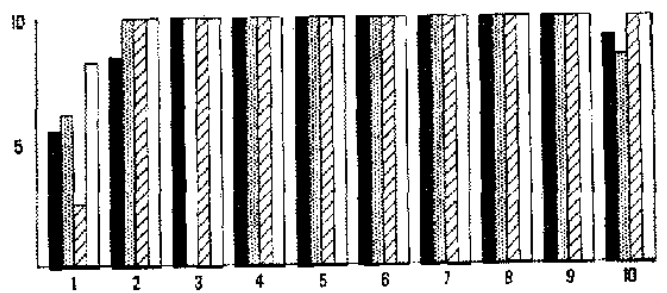

Fig. 4. A pattern for the differentiation of germ cells in the evary at $9.0 \mathrm{~mm}$ stage. $\mathrm{n}=9$.

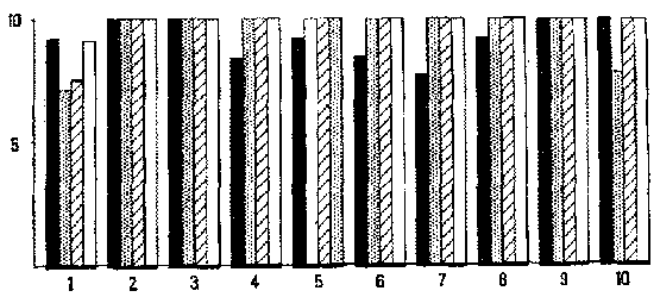

Fig. 5. A pattern for the differentiation of germ cells in the ovary at $10.0 \mathrm{~mm}$ stage. $\mathrm{n}=6$.

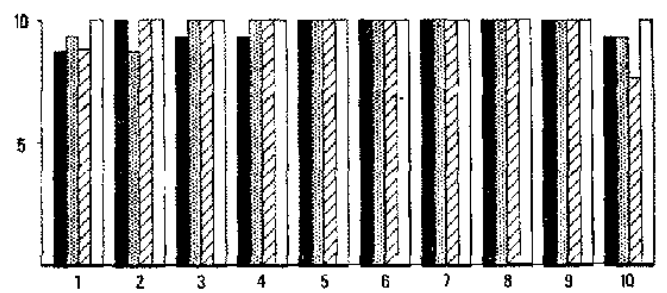

Fig. 6. A pattern for the difierentiation of germ cells in the ovary at $11.0 \mathrm{~mm}$ stage. $\mathrm{n}=4$.

3), and the other type contained a few germ cells (Plate, 4). At this stage, germ cell in meiosis was not detected at all. At 2 days $(26 \pm 2 \mathrm{~h})$ after hatching, germ cells in meiotic prophase were observed in the former gonads, but the somatic elements of the gonad showed no structural differentiation. Among 30 fry examined bistologically, 12 fry contained the germ cells in leptotene and zygotene stages (Plate, 5). Their body length was $4.9 \pm 0.10 \mathrm{~mm}$ (mean \pm S.D., $n=30$ ). In a previous paper ${ }^{13)}$, we already reported that the onset of meiosis in the testis was at the stage of $11.5 \mathrm{~mm}$. So, the gonads with germ cells in meiosis were regarded as ovaries.

At the time of numerical analysis, we confronted two interesting and troublesome phenomena. In the adult medaka, both testis and ovary are unpaired organs suspended in the coelom between the mesonephric duct and the gut in the posterior 


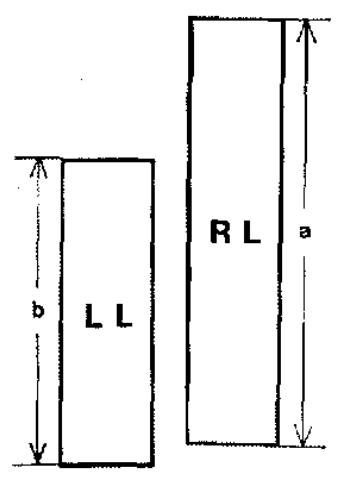

Fig. 7. Schematic representation of the dorsal view of the right lobe (RL) and the left lobe (LL) of the ovary. The length of the left lobe was about $60 \%$ of that of the right lobe. $b / a=0.56 \pm 0.19$ $(m e a n+S . D$., $n=48$ ). Besides, the right lobe tended to locate at the more cephalic position than the left lobe. In this and next figures, the upper of the figure indicates the cephalic direction.

trunk region. In the fry, however, the gonads are originally paired organs located bilaterally at the root of mesentery. As already reported by YAMAMoTo ${ }^{14}$, germ cells are asymmetrically distributed to the lobes of the gonad, the right lobe receiving the larger number of germ cell. We compared both right and left lobes by means of their length instead of their number. As shown in Fig. 7, the length of the left lobe was about $60 \%$ of that of the right lobe. Besides, the right lobe was found to be located at the more cephalic position than the left lobe. Then, we dealed with the right lobe and the left lobe separatedly at these stages. At about 6.0 $\mathrm{mm}$ stage, the right and the left lobes came to be fused with each other, and formed an unitary organ. Examining the differentiation of the right and the left lobes of an ovary, we noticed that only the right lobe contained oocytes and the left lobe contained germ cells at gonium stage. The difference in the time of sex differentiation between the right lobe and the left lobe was recognized in 3 out of 12 females at 2 days after hatching, 2 out of 14 at 3 days, 1 out of 11 at 4 days and 1 out of 11 at 5 days. An opposite case that only the left lobe contained oocytes was not detected at all. It is perhaps assumed that the right lobe differentiates at an earlier stage than the left lobe.

The other phenomenon is described schematically in Fig. 8. Observing the successive sections including gonadal area in cephalo-caudal sequence, we can see at first only the right lobe owing to its more cephalic position (Plate, 6), and both lobes

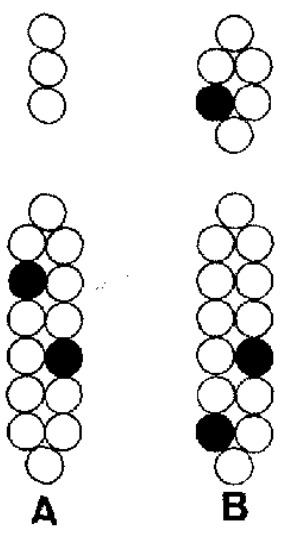

Fig. 8. Schematic representation of the dorsal view of a lobe consisted of anterior smaller piece and posterior larger piece. One type (A) contained only germ cells at gonium stage in the anterior piece. The other type (B) contained oocytes in the anterior piece. The separated lobes like $A$ and $B$ were recognized in 4 out of 12 females at 2 days after hatching, 3 out of 14 at 3 days, 4 out of 11 at 4 days and 2 out of 11 at 5 days. oogonium, oocyte.

in some posterior sections (Plate, 7). But, in the more posterior sections either lobe suddenly disappeared (Plate, 8), and again appeared in the far more posterior sections. These lobes were divided into two types owing to the presence or the absence of oocyte in the separated anterior piece. The lobe consisted of two pieces was regarded as an unitary lobe for convenience in the present investigation. This phenomenon means that the ovarian differentiation begins before the completion of the formation of the primordial gonad.

The results of the numerical analysis are shown in the bar charts of Figs. 9-12. If ovarian differentiation progresses in antero-posterior sequence in a strict sense, germ cell in meiosis should begin to emerge at the most anterior part, " 1 ". Unexpectedly, however, from the very beginning when germ cells in meiosis were detected, they were found to be present at random. Moreover, they tended to emerge at the rather posterior region of ovary than the anterior region. It may be concluded that the ovarian differentiation proceeds without any gradient similarly to the testicular differentiation.

\section{Discussion}

Since YaMAMOTO ${ }^{14)}$ achieved the functional feminization of the genetic male of the medaka by oral 

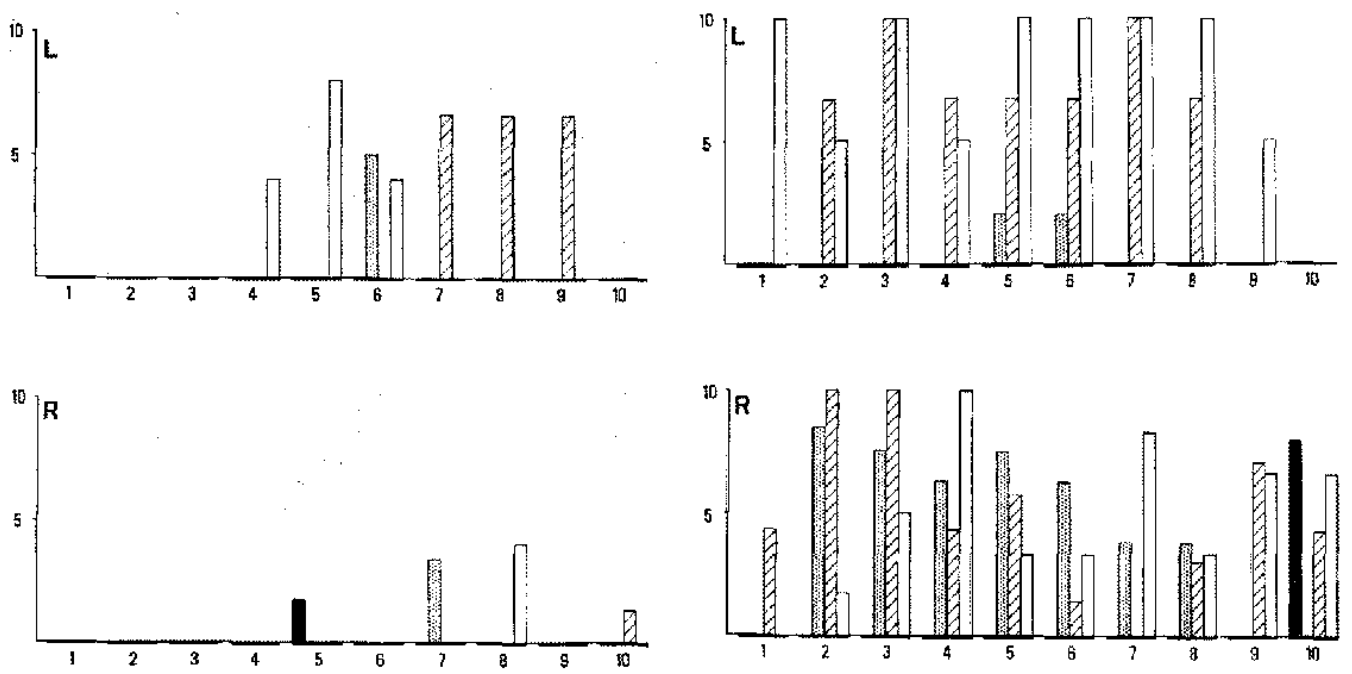

Fig. 9. Patterns for the differentiation of germ cells in the right lobe (R) and the left lobe (L) of the ovary at 2 days $(26 \pm 2 \mathrm{~h}$ ) after hatching. $\mathrm{n}=30$. 旗 Their body length was $4.9+0.10 \mathrm{~mm}$ (mean S. D.).
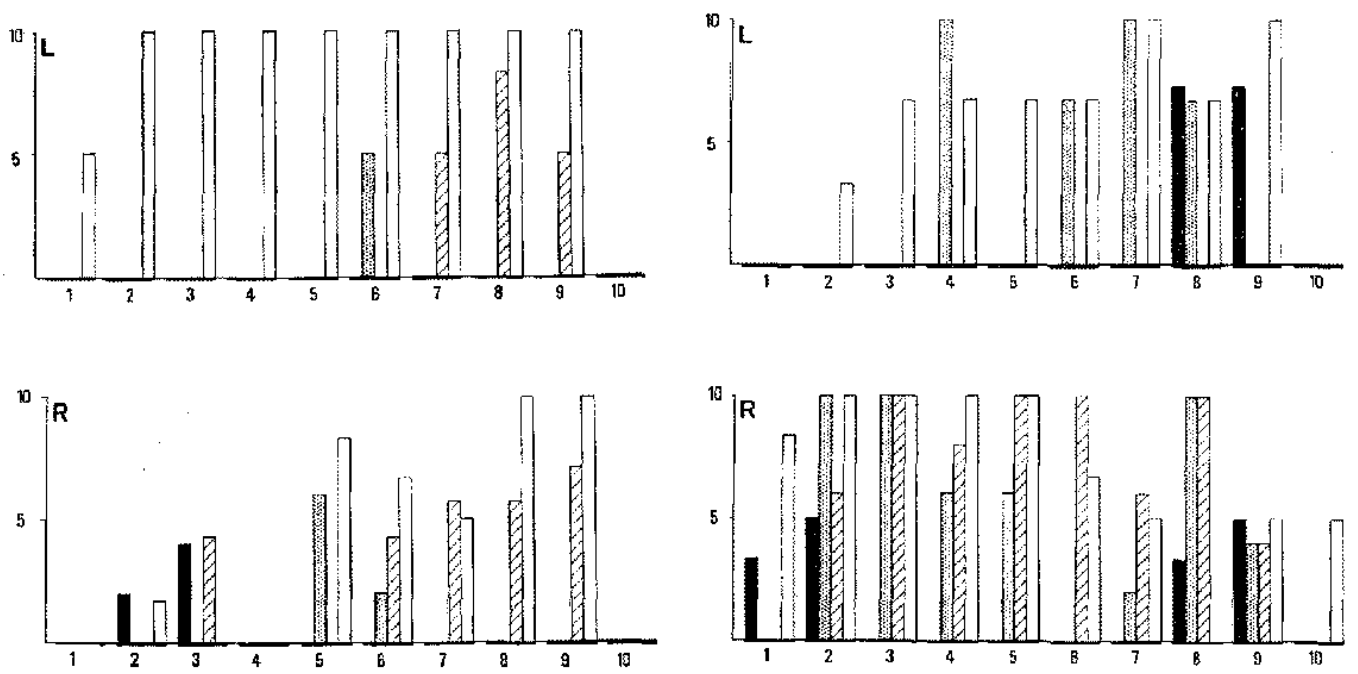

Fig. 10. Patterns for the differentiation of germ cells in the right lobe $(R)$ and the left lobe (L) of the ovary at 3 days $(50 \pm 2 \mathrm{~h})$ after hatching. $n=$ 30. Their body length was $4.9 \div 0.13 \mathrm{~mm}$ (mean + S. D.).

administration with estrone, the successful cases in artificial sex reversal have been reported in several fishes ${ }^{x, 18-22)}$. Generally speaking, however, it took the longer period of hormonal treatment to cause a complete sex reversal. For instance, the minimum period of hormonal treatment for $100 \%$

Fig. 11. Patterns for the differentiation of germ cells in the right lobe (R) and the left lobe (L) of the ovary at 4 days $(74-2 \mathrm{~h})$ after hatching. $n=30$. Their body length was $5.0 \pm 0.20 \mathrm{~mm}$ (mean $t$ S.D.).

Fig. 12. Patterns for the differentiation of germ cells in the right lobe $(R)$ and the left lobe $(L)$ of the ovary at 5 days $(98 \pm 2 \mathrm{~h}$ ) after hatching. $n=30$. Their body length was $5.2 \pm 0.23 \mathrm{~mm}$ (mean \pm S.D.).

sex reversal was from 6 to $11 \mathrm{~mm}$ stage in the meda $\mathrm{ka}^{3)}$, and the period was not shortened by the elevation of the dosage level of steroid hormones's?. YAMAMOTO reported again and again that there was an antero-posterior gradient in gonadal sex differentiation of the medaka. And, he stated that 
sex differentiation began at $6.3 \mathrm{~mm}$ stage and finished at about $11 \mathrm{~mm}$ stage ${ }^{37}$. If such a gradient really exists and the minimum period is from 6 ot $11 \mathrm{~mm}$, the reason for the longer period of hormonal treatment may be explained as given below. The responsiveness of gonad to exogenous steroid hormones proceeds in an antero-posterior sequence If the hormonal treatment is carried out for the period of 8 to $9 \mathrm{~mm}$, the gonad of genetic female will be consisted of ovarian tissue in the anterior and the posterior regions and testicular tissue in the middle region of the gonad. Accordingly, hormonal treatment should be done for the period of 6 to $11 \mathrm{~mm}$ to obtain a complete sex reversal. In the present investigation, however, ovarian differentiation was recognized for the first time in the fry of $4.9 \pm 0.10 \mathrm{~mm}$ in length at 2 days $(26 \pm$ $2 \mathrm{~h})$ after hatching, and proceeded without any gradient. SATOH and EGAMI ${ }^{24}$ reported that out of 43 newly hatched fry of the medaka within $24 \mathrm{~h}$ after hatching, 6 fry were observed to contain germ cells in meiosis, and ONITAKE ${ }^{253}$ also reported that the gonad of some newly hatched fry $(4.5 \mathrm{~mm}$ in length) possessed germ cells in meiosis. These reports are well in agreement with the present results. Furthermore, also in the testicular differentiation of the medaka, such a gradient was not recognizable ${ }^{132}$.

On the basis of the findings obtained by himself and his co-workers in the medaka, YAMAMOTO ${ }^{23}$ suggested that hormonal treatment should be done, in order to attain a complete sex reversal, beginning at the sexually indifferent stage and continuing through the stage of sex differentiation. According to Hishid ${ }^{23}$, however, the critical period for sex reversal of genctic female was at about $9 \mathrm{~mm}$ stage in the medaka. From the present investigation, it is evident that ovarian differentiation is completely finished at this stage. In this connection, TAKAHASH ${ }^{28)}$ suggested a hypothesis that germ cell at gonium stage retained a bisexuality for a long time after the onset of sex differentiation in the guppy, Poecilia reticulata. As mentioned before, sex differentiation of Xenopus laevis progressed in an antero-posterior sequence for about a week, and the gonad of genetic male treated with estrogen for 2 days within the week of sex differentiation developed into a mosaic gonad, consisted of ovarian and testicular components. In this mosaic gonad, the ovarian part corresponded to the differentiating part at the time of hormonal treatment ${ }^{8-10}$. A similar effect of steroid hormone was reported in a frog, Rhacophorus arboreus.
According to IWASAwA et al. ${ }^{27}$, hormonal treatment with androgen for 2 days caused the genetic female gonad of $R$. arboreus to develop into a hermaphroditic gonad, composed of ovarian and testicular elements as in the case of $X$. laevis. Differently from that in $X$. laevis, however, the position of the testicular part was not connected with the time of hormonal treatment. W'TSCHI ${ }^{8)}$ pointed out that hormonal treatment before the start of sex differentiation was not effective in inducing a mosaic gonad. In other words, germ cells before sex differentiation did not have the responsiveness to steroid hormones. These reports $^{8-10,27)}$ indicated that there was a difference in the time to gain the sensitivity and the responsiveness to steroid hormones among germ cells regardless of the presence of a gradient in sex dif* ferentiation. The reason why sex reversal was caused by hormonal treatment given after sex differentiation in fishes may be explained in the following way. In the newly differentiated gonad, three types of germ cells exist: indifferent germ cells which do not have the responsiveness to steroid hormones yet, differentiating germ cells which have it now and differentiated germ cells which renounce it and can be induced no longer in opposite direction. It is noted that "indifferent", "differentiat" ing" and "differentiated" are the terms used for convenience owing to the presence of the respotisiveness to steroid hormones, never mean the true sense of differentiation, and that the gonads of all the fish species do not always have the responsiveness to exogenous steroid hormones. Furthermore, it remained unknown whether the effect of steroid hormones on germ cell is direct or indirect through the somatic elements of the gonad. Concomitantly with the increase of differentiated germ cells in number, the gonad as a whole reduces the responsiveness gradually on account of the decrease in number of indifferent germ cell and differentiating germ cell. $U p$ to the time when the gonad is occupied with differentiated germ cells to a certain extent, the gonad can be reversed in opposite direction by the proliferation of indifferent germ cell and the degeneration of differentiated germ cell. Eventually, the gonad gives up the responsiveness to steroid hormones at a certain time; the time is a critical point for artificial sex reversal.

\section{Acknowledgements}

We wish to thank Professor T. TAMURA, Faculty 
of Agriculture, Nagoya University, for his continuous interest and valuable comments throughout the study. We are indebted to Dr. H. TomTa, Faculty of Science, Nagoya University, for kindly supplying the d-rR strain of the medaka. We also wish to thank Mrs. K. KogA for typing the manuscript and photographing.

\section{References}

1) H. Yoshukawa and M. OGurJ: Bull. Japan. Soc. Sci. Fish., 44, 313-318 (1978).

2) T. Yamamoto: J. Exp. Zool., 141, 133-153 (1959).

3) T. Yamamoto: Gen. Comp. Endocrinol, Suppl. 1, 341-345 (1962).

4) T. Yamamoto and N. Matsuda: Gen. Comp. Endocrinol, 3, 101-110 (1963).

5) T. Yамamoto: J. Exp. Zool., 137, 227-264 (1958).

6) T. Yamamoto: J, Fac. Sci. Hokkaido Univ. Ser. $V I, 13,440-444$ (1957).

7) T. Yамамото: Gen. Comp. Endocrinol., 5, 527-533 (1965).

8) E. WITSCHI: in "The Biochemistry of Animal Development" (ed. by R. Weger), Vol. 2, Academic Press, New York, 1967, pp. 193-225.

9) C. Y. Chang and E. Witschi: Proc. Soc. Exptl. Biol. Med., 93, 140-144 (1956).

10) E. Witschi and E. Dale: Gen. Comp. Endocrinol. Suppl. 1, 356-361 (1962).

11) E. WirschI: J. Exp. Zool., 52, 235-265 (1929).
12) R. R. Humphrex: J. Exp. Zool, 65, 243-269 (1933).

13) H. Yoshikawa and M. OGurt: Bull. Japan. Soc. Sci. Fish., 45, 1115-1121 (1979).

14) T. Yamamoto: $J$. Exp. Zool., 123, 571-594 (1953).

15) T. Yamamoto and T. Kajlshima: J. Exp. Zool, 168, 215-222 (1968)

16) H. P. Clemens and T. Inslee: Trans. Amer. Fish. Soc., 97, 18-21 (1968).

17) M. NaKamura and H. Takahashi: Bull. Fac. Fish. Hokkaido Univ., 24, 1-13 (1973).

18) H. TaKahashl: Bull. Fac. Fish. Hokkaido Univ., 26, 223-234 (1975).

19) H. Takahashi: Develop. Growth Differ., 17, 167-175 (1975).

20) H. OKaDA, H. Matumoto, and F. Yamazaki: Bull. Japan. Soc. Sci. Fish., 45, 413-419 (1979).

21) B. Jalabert, J. Moreau, P. Planquette, and R. Billard: Ann. Biol. anim. Bioch. Biophys., 14, 729-739 (1974).

22) F. YamazaKI: J. Fish. Res, Board Can., 33, 948-958 (1976).

23) T. Hishida: J. Predent. Fac., Gifu Coll. Dent., 1, 81-101 (1975).

24) N. SAтоH and N. Egam: J. Embriol. exp. Morph., 28, 385-395 (1972).

25) K. ONITAKe: Annot. Zool. Iapon., 45, 159 169 (1972).

26) T. Yамамото: in "Fish Physiology" (ed. by W. S. Hoar and D. J. Randall), Vol. 3, Academic Press, New York, 1969, pp. 117-175.

27) H. Iwasawa, T. Mardyama, and S. Tsukada: Sci Rep. Niigata Unis., Ser. D., 16, 29-34 (1979).

\section{Explanation of Plate}

Transeverse sections of the gonads in the medaka.

1. Ovary at $5.5 \mathrm{~mm}$ stage. $\times 440$.

2. Ovary at $9.0 \mathrm{~mm}$ stage. $\times 145$.

3. Gonad with many germ cells (ovary?) in the newly hatched fry. $\times 385$.

4. Gonad with a few germ cells (testis?) in the newly hatched fry. $\times 385$.

5. Ovary at 2 days after hatching. Arrows show the oocytes in leptotene and zygotene stages. $\times 550$.

6-8. Three parts of an ovary at 5 days after hatching. $\mathbf{L L}$, left lobe of ovary; RL, right lobe of ovary. $\times 410(6), \times 530(7), \times 385(8)$. 
Plate

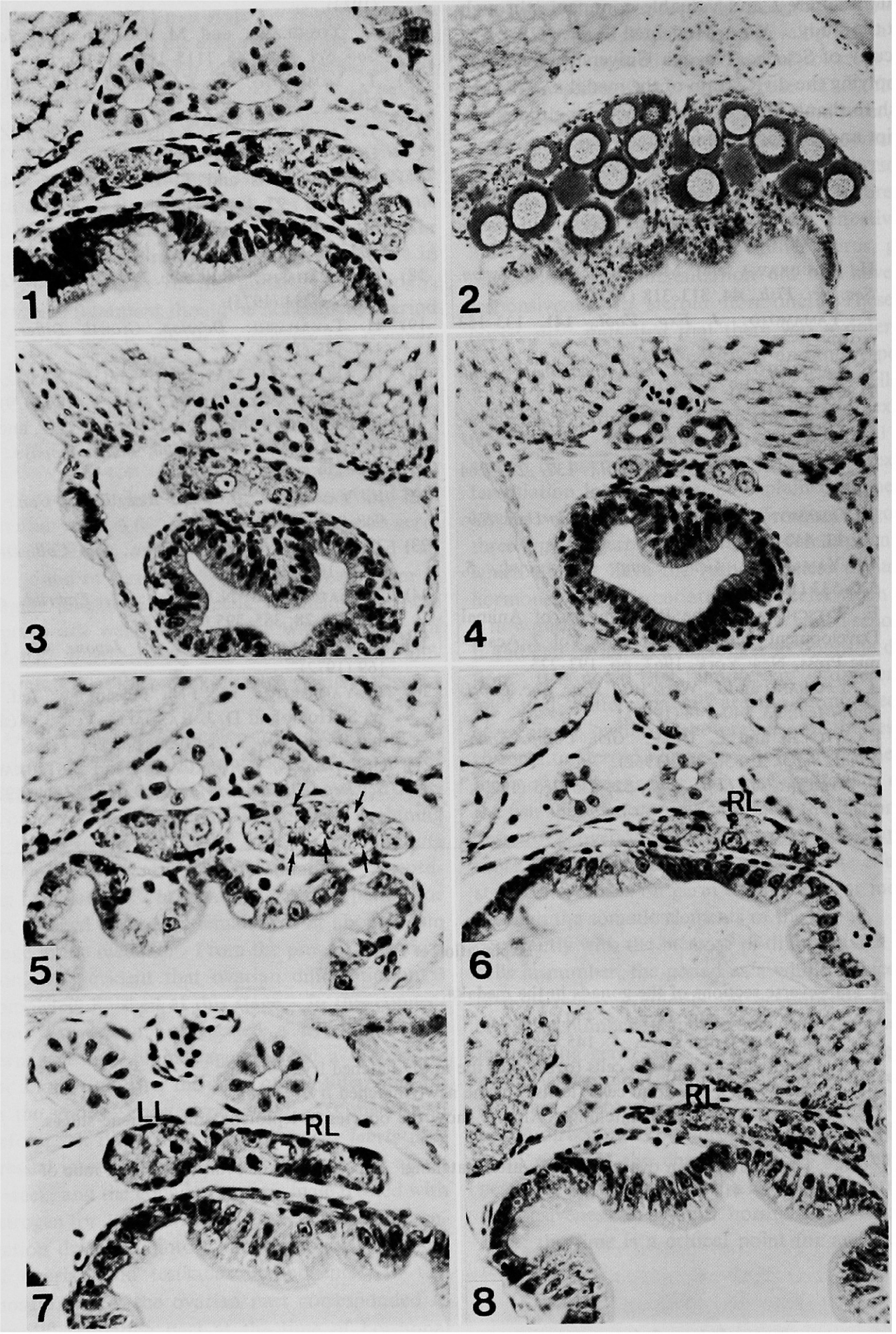

